Artículo

\title{
Alberto Masferrer y la Educación Vitalista en El Salvador
}

\author{
Alberto Masferrer and the vitalist education in El Salvador \\ Víctor Manuel Guerra Reyes* \\ victor.guerra@udb.edu.sv
}

ISSN 1996-1642, Editorial Universidad Don Bosco, año 8, No.13, Enero-Junio de 2014, pp.7-18

Recibido: 15 de diciembre de 2013. Aceptado: 23 de enero de 2014.

Resumen

Este artículo trata sobre los principios fundamentales de la Educación Vitalista que propuso Alberto Masferrer a la sociedad salvadoreña de principios del siglo XX. Este pensador sostenía que todo ciudadano que supiera leer y escribir debía enseñar a quien no supiera y que los gobiernos de turno debían diseñar y organizar las políticas educativas en función de la vida de los salvadoreños. Además mostró que la Educación necesariamente está vinculada al ámbito de la justicia social de los pueblos que se educan.

Palabras clave: educación, vitalismo, vida, justicia social, salvadoreños.
Abstract

This paper approaches the main principles of the vitalist education proposed by Alberto Masferrer to the Salvadoran society at the beginning of the $X X$ century. This thinker stated that every citizen being able to read and write should teach to whom did not know how and that the ruling government should design and implement the educational policies around the Salvadoran way of life. Besides, he brought out the link between social justice and the people being educated.

Keywords: education, vitalism, life, social justice, Salvadorans.

\footnotetext{
* Licenciado en Filosofía, Maestría en Teología, Doctor en Filosofía lberoamericana y Docente investigador
} 
"Tal como la vida se halla organizada en nuestros tiempos, un pueblo analfabeto será, sin remedio, el esclavo de un grupo de perversos de su propio suelo, o la presa fácil de cualquier nación poderosa que desee absorberlo o dominarlo." A. Masferrer.

\section{Introducción}

La educación del ser humano es clave para que la sociedad se desarrolle ante los retos y exigencias que implica vivir en un mundo tan complejo como es el mundo del siglo XXI.

El sistema capitalista para mantenerse como sistema imperante ha organizado la cultura de una forma tal que la escuela, la familia, la religión, el derecho y todo el sistema de ideas se ha organizado como un constructo que funciona sistemáticamente orientado a perpetuarse a sí mismo. En este orden de cosas, lo más importante para el sistema es la economía que se presenta con su mejor representante, la mercancía y el mercado, como algo absoluto que lo determina todo y donde todo se puede comprar o vender, siempre y cuando se esté en las posibilidades de participar dentro de este mundo que implica el mercado. Quien más dinero posee, puede comprar casi todo lo que desee.

En este contexto, la educación es pieza fundamental para que el sistema funcione y se perpetúe; de ahí que en este sistema lo más importante no es la defensa de la vida sino la defensa del mercado. En este sentido, es comprensible que se priorice sobre todo los conocimientos que permitan mayor ganancia, que incrementen al máximo la producción y que mejore la relación entre la oferta y la demanda y por supuesto, en esta lógica, la vida humana pasa a un segundo plano que no es relevante para nada, todo lo contrario, es accesoria y pieza fácilmente reemplazable en el sistema mercantil.

Esto es lo que se ha vivido en El Salvador desde épocas ancestrales y, como lo que ha exigido el capital en este país es mano de obra barata, la educación formal ha priorizado de manera exagerada la formación y cualificación técnica, en detrimento de una verdadera educación que priorice y cualifique al ser humano para que busque una mejor forma de vida.

Alberto Masferrer puso en autos a la sociedad salvadoreña de principios del siglo XX con el interés de que los gobiernos de turno organizaran las políticas educativas en función de la vida de los salvadoreños que estaba constituida fundamentalmente por personas pobres y marginadas en el sentido social, económico y político. 
organiza este escrito en tres partes principales. La primera parte constituye un esbozo de la figura del maestro Masferrer, la segunda trata del pensamiento vitalista masferreriano y la tercera constituye una síntesis de la educación vitalista.

\section{Aproximación a la figura y obra de Alberto Masferrer}

Alberto Masferrer (1868-1932), nació en Tecapa, actual municipio de Alegría, en el departamento de Usulután, El Salvador. Sus más preciados e importantes escritos giran en torno a la realidad salvadoreña. Escribió Novela, Ensayos y Reflexión sociopolítica. Sus obras más leídas son: Leer y Escribir, La Doctrina del Mínimum Vital", El Dinero Maldito, Una vida en el Cine, ¿Qué debemos Saber?, El Libro de la Vida, Las Siete Cuerdas de la Lira, La Religión Universal, Ensayo Sobre el Destino, Estudios y Figuraciones sobre la Vida de Jesús, Patria, entre otros. Patria constituye una colección de artículos periodísticos de contenido político, educativo, económico y filosófico que aparecieron como editoriales del periódico Patria desde 1928 hasta 1930.

Masferrer es uno de los autores que más ha influido en la realidad salvadoreña de principios del siglo XX. Fue el ideólogo de la campaña política del presidente Arturo Araujo, quien un año después de ganar las elecciones fue depuesto por un golpe de Estado dirigido por el militar y luego dictador salvadoreño Maximiliano Hernández Martínez.

\section{Aproximación al Vitalismo masferreriano}

En términos generales, el Vitalismo es aquella filosofía cuya tesis fundamental es que la vida es irreductible a cualquier categoría extraña a ella misma. Como afirma Urdanoz (1998), esta doctrina hace de la vida el valor supremo o la realidad última y unificante de las formas concretas de lo real. Hirschberger (1992), por su parte, afirma que las corrientes vitalistas se diferencian por su concepto de vida: la comprensión de la vida en el sentido biológico subraya el papel del cuerpo, los instintos, lo irracional, la naturaleza, la fuerza y la lucha por la subsistencia.

El vitalismo no es simplemente una teoría, sino una praxis. La praxis es aquella acción humana que conlleva inmersa dentro de sí mismo la reflexión consciente del sujeto que la ejecuta. Es decir, que cuando nosotros hacemos una actividad cualquiera y nos vamos cuestionando por qué la hacemos, cómo la podemos realizar de forma más eficiente o por qué no dejamos de hacerla para hacer

1 Nótese que en el texło aparecen los términos minimum y mínimun en aparente confusión. Alberto Masferrer usualmente escribe la palabra mínimun con tilde, como una palabra esdrújula, y con " $n$ " al final con el claro interés de castellanizar el vocablo para referirse a lo mínimo. El autor del artículo, sin embargo, usa el término minimum, tomado en su forma original del latín para referirse al mismo concepto, pero retoma la escritura de Masferrer cuando se cita textualmente. 
otras más provechosas, estamos realizando la praxis. La praxis por tanto es la actividad humana consciente que nos aparta del activismo.

Esto quiere decir que toda acción debe estar ubicada en un tiempo y en un espacio. Un tiempo, el de ahora, nuestro tiempo, 2014 y en El Salvador, no en Rusia, China, Venezuela, la Luna, etc., sino hic et nunc como decían los latinos, aquí y ahora. Esto no solo nos ubica en el tiempo y el espacio concreto, sino que además nos coloca un referente válido, nuestra gente, a quienes amamos, con quienes nos peleamos, con quien hacemos nuestra vida. Aquí cobra vital importancia lo que afirmaba uno de los grandes defensores del vitalismo, el filósofo español Ortega y Gasset (2004, p. 322), que afirmaba que "yo soy yo y mis circunstancias y si no las salvo a ellas no me salvo yo". Es decir, que nuestra vida se salva en la vida, en nuestra vida, ésta que estamos viviendo y no en otra.

Ahora bien, el mejor representante del Vitalismo que nosotros los salvadoreños y centroamericanos tenemos es Alberto Masferrer que, como figura intelectual es uno de los más decididos defensores y precursores de los derechos humanos en occidente.

A diferencia de otros autores que piensan que Masferrer expresó su mejor formulación del Vitalismo en su obra El Minimum Vital publicada en 1929, quizá tomando como base la expresión propia del mismo Masferrer que afirmó que en dicha publicación se encontraba formulada la versión más acabada del Vitalismo (Masferrer, 1929). Aunque esta afirmación sea clara y exprese verdad al respecto; aquí se sostiene que la obra cumbre que cristaliza los principios filosóficos, educativos, sociales y políticos del pensamiento Vitalista de Masferrer, está mejor lograda en los artículos periodísticos que este pensador publicó en el periódico Patria durante los años de 1928 a 1930. Como lo mencionara el mismo Masferrer, El Mínimum Vital no es una aplicación del Vitalismo a la sociedad humana sólo desde el punto de vista económico ya que ésta es en realidad una doctrina sintética de la vida, que es a la vez filosofía, religión, arte, ciencia, moral, economía y derecho (Masferrer, 1929).

Como sostiene el mismo Masferrer, una aplicación de esta doctrina a la Sociedad humana, desde el punto de vista meramente económico, es la que esbocé en mi ensayo, titulado El Mínimun Vital, cuya síntesis dice: que el Régimen Social puede y debe organizarse de tal manera, que para todos los asociados haya la posibilidad segura de disfrutar de un Mínimun de Vida Integra. (Masferrer, 1971, p. 190).

Alberto

Masferrer y la Educación Vitalista en El 10. Salvador
En los artículos que Masferrer publicó en el periódico Patria, se encuentra evidenciado en toda su madurez el pensamiento filosófico en su vertiente 
política de la teoría Vitalista. En este marco, el Vitalismo como pensamiento filosófico político de corte latinoamericanista, está concentrado en tres editoriales de Patria, de los días 1, 2 y 3 de octubre de 1928, denominados La Misión de América. Es decir que el itinerario seguido por Masferrer en conseguir una mejor formalización del Vitalismo, lo culmina en estos artículos. Y el proceso lo inicia proponiendo la transformación del modus vivendi individual, pasando por el ámbito de transformación de la familia como núcleo de la sociedad y culminando con la transformación de la sociedad entera. Argumento bien articulado y expresado en este escrito que incluye además, el agente dinamizador de esta transformación práctica que lo constituyen las instituciones educativas del Estado y la nación, especialmente la escuela y la universidad.

El pensamiento filosófico político de Masferrer cobra fuerza a principios del siglo veinte, no sólo en El Salvador, sino también en el resto de Centroamérica. En Guatemala, por ejemplo, el gobierno del General Lázaro Chacón (19271930) organiza su programa de gobierno basado en los principios del Vitalismo masferreriano. En el contexto de saber cuáles son los principios de esta doctrina, Masferrer fue invitado reiteradamente a Guatemala a explicar su teoría.

Como afirmara el mismo Masferrer:

En Quezaltenango, en el Casino de la ciudad, los millonarios de la región se congregaron para oír una detenida exposición de la Doctrina del Mínimun Vital. Fueron ellos, los ricos, los terratenientes los banqueros los grandes comerciantes, los grandes cafetaleros de la Costa, quienes nos invitaron reiteradamente a ir a su Centro, a exponer la Doctrina Vitalista, y durante tres horas nos escucharon con atención profunda, con exquisita cortesía, con la elegante actitud del hombre culto. (Masferrer, 1971, p. 563).

En este pensamiento filosófico se expone la defensa y construcción de la vida, como elemento fundamental de toda expresión y práctica humana. Aquí, la defensa de la vida, es una especie de clave hermenéutica para la formulación de toda construcción de pensamiento. Este carácter es ineludiblemente político.

En la concepción filosófica de Masferrer la vida tiene un carácter político y por tanto es la clave hermenéutica del vitalismo en el sentido siguiente: Para Masferrer la vida es una, es un bien supremo y su superioridad respecto de todo lo demás es de carácter absoluto (Masferrer, 1971). Esta vida, comprendida a la manera masferreriana no es abstracta ni metafísica sino material y "animal, concreta, visible y tangible, determinada de la forma más concreta y práctica (Masferrer, 1971). De ahí que defender la vida en todas sus manifestaciones es el mandamiento primero y supremo y a él nos atenemos los creyentes del 
Vitalismo para juzgar de los conflictos del presente, y para idear y preparar un Nuevo Orden Social que suprimirá o atenuará los más graves de esos conflictos (Masferrer, 1971).

Por su parte, la escritora Matilde Elena López (1925-2010), haciendo un itinerario por la vida de Masferrer, afirma que en los últimos cinco años de vida de este autor las ideas del Vitalismo se esclarecieron, se enlazaron y se ordenaron en su pensamiento alcanzando una cristalización que denominó "doctrina sintética de la vida, que es a la vez filosofía, religión, arte, ciencia, moral, economía y derecho. Una aplicación de esta doctrina a la sociedad humana desde el punto de vista meramente económico, es la que esbocé en mi ensayo titulado El Mínimum Vital, cuya síntesis dice; que el Régimen Social puede y debe organizarse de tal manera, que para todos los asociados haya la posibilidad segura de disfrutar de un mínimum de vida integra (López, 1962).

Con la formulación del Vitalismo, Masferrer construye un pensamiento filosófico político en cuya base se encuentran tres elementos históricos: el pensamiento oriental, el socialismo fabiano y la realidad salvadoreña de finales del siglo XIX y principios del siglo XX.

\section{La educación vitalista}

Para Masferrer, la educación es una función social que no puede dejarse únicamente en manos de ningún gobierno. Es más, si sólo a él se le encomendara esa función, juzgando las circunstancias de la época en que escribió Leer y Escribir (1913) y ¿Qué debemos saber? (1915), el gobierno podía cumplirla muy pobremente. Por desgracia, la educación no ha sido una prioridad para los gobiernos y a juicio de Masferrer, esto contrasta con la realidad, porque educar a las clases desposeídas, que es donde se encuentra y crece sin medida el analfabetismo, es una necesidad urgente para el verdadero desarrollo humano de El Salvador y de cualquier país.

Ahora bien, la propuesta práctica para educar a las mayorías salvadoreñas y cumplir ese compromiso fue siempre pedir que toda persona que supiera leer y escribir debía convertirse en educadora de analfabetos; es decir, sugería una labor privada de la educación. Ahora bien si el Estado colaboraba en esta importante misión, su ayuda sería bienvenida en todo momento.

Pero esto en realidad era una crítica contundente contra el estado de cosas organizado por los distintos gobiernos que no proveía educación y menos educación de calidad a la inmensa cantidad de seres humanos atrapados 
no eran capaces de poner freno a los abusos, al egoísmo y a la prepotencia de los potentados. En esto Masferrer fue enfático cuando dijo que:

Aquí se ha creído que hay cultura pero no la hay. A una razón se contesta con un insulto, generalmente escudado en el anónimo. A un hombre que pide mejor vivienda para los miserables; y mejor pan y más trabajo, se le llama bolchevique, el vitalismo no predica la violencia; no quiere el despojo sino el respeto a lo de cada uno. Y sin embargo, en lugar de que los opositores contesten argumentos con argumentos y nos convenzan de un errar en el cual -al cabo humanos- podríamos incurrir, nos escarnecen, nos insultan, nos calumnian. Pero el pensamiento está en marcha. Y les arrollaremos con la idea, porque todavía no ha nacido hombre que pueda luchar contra ella victoriosamente (Masferrer, 1929, pp. 1-2).

Para Masferrer todos los hombres y mujeres deben emanciparse de las cadenas de la ignorancia. En el caso de los obreros, se dirigía a ellos diciendo que "aceptando que la condición de obrero no es esencial ni principal en el hombre, sino accidental y subordinada (pues consiste simplemente en una de tantas maneras de ganarse la vida), la pregunta ¿qué debe saber un obrero para ser instruido? Ya no tiene razón de ser, y debe sustituirse por esta otra: ¿Qué debe saber un hombre para ser instruido? He aquí la cuestión en su verdadero terreno (Masferrer, 1971). En esta perspectiva, como afirma Masferrer, "si el hombre, cada hombre, no se emancipa de la bestialidad, el conjunto, el conglomerado social no puede ser sino un tropel de bestias. En este contexto afirmaba, no ha mucho Krisnamurti, [sic] que el problema del individuo es el problema de mundo" (Masferrer, 1971, p. 199). Por tanto, hay que cambiar todo el supuesto orden que se ha establecido desde mucho tiempo atrás, ya que este orden no está organizado en función del ser humano ni de la vida:

Si tenemos esas leyes y esas religiones y esa moral. Las tenemos aún, y han durado mucho, y han causado inmenso daño, y nos han sumergido en tinieblas tan espesas, que ya se hace casi imposible recordar por qué rumbo se ocultó el sol, ni saberse por dónde volverá. Mas ahora, deben morir. Debemos desembarazarnos de ellas con resolución y premura; debemos crear y organizar una nueva y más alta concepción de la vida, en la ley, la educación, las costumbres, todo se halle subordinado francamente al bien del niño, cuyos derechos no admiten tasa ni medida, ni restricción ni prescripción. (Masferrer, 1971, p. 212).

Masferrer (1971) afirma que esta situación de iniquidad tiene una causa fundamental que hay que superar necesariamente, porque es la realidad provocada por el acaparamiento de la tierra y todo el sistema capitalista 
organizado en El Salvador, bajo este principio se trastoca los valores y convierte en ideologización todo valor.

Es en esta perspectiva que la historiadora Marta Casaús Arzú (Casaús Arzú, 2012), afirma que para Masferrer,

La educación no es un simple rubro entre las necesidades sociales, es un proyecto complejo de su doctrina vitalista que es, a la postre, el proyecto macro de su obra. Por lo tanto trasciende la escuela como institución y abarca la sociedad en su conjunto. La educación se atiende en las aulas de las escuelas y la universidad, pero también en el teatro, el cinematógrafo, la prensa y lo libros; la escuela de artes y el comercio de cuadros y esculturas; las conferencias y los cursos libres; la ornamentación de los sitios públicos; la conservación de los monumentos tradicionales; la difusión de la buena música y de la buena pintura: en fin, arte, ciencias, ideales y costumbres. (p. 212).

Como bien afirma Masferrer (1971), que quien se conforme con que las cosas sigan como él las encontró, como los demás se las dan hechas, como la tradición y la rutina las modelaron, y se acomoda a vivir entre los rincones polvorientos de ideas rancias, de sentimientos vulgares y de hábitos enmohecidos, no es ciertamente un hombre en el noble sentido de la palabra, no es un humano sino un animal que ya alcanzó la forma, pero todavía no el espíritu de humanidad. Lo mismo se aplica esta caracterización a los pueblos que a los individuos. Los pueblos que se han cultivado intelectualmente con una educación crítica y realista con la vida son

Pueblos fuertes, cargados de vigor, serán necesariamente expansivos y querrán modelar el mundo a su propia imagen. En forma de conquista armada, de expansión comercial, de influencia literaria o científica, de imposición de sus leyes o de su idioma, de imperio de sus modas o de su religión o de su moneda, el pueblo cargado de vida, de fuerza pugnará inquieto, sugerente y aún progresivo, para salirse de sí mismo, rebasar el cauce de sus modalidades, infundirse o transfundirse en los demás y hacer de ellos imágenes suyas, variaciones o repeticiones del tema que encierra, su propio yo, expresado en forma de cultura (Masferrer, 1971, p. 454).

Todo lo contrario puede decirse de aquellos individuos y pueblos que permanecen en la inanición, son como seres sin espíritu-aglomeraciones de hombres en un territorio- sin más deseo que vivir animalmente, gozando de su propia comida y su bebida, no realizan ningún esfuerzo para alcanzar una cultura original, y menos aún para extenderla más allá de sí mismos (Masferrer, 1971). Se comportan por la vida "como arcilla, pasivos y plasmables y lo reciben todo, 
inertemente del azar, de la tradición, de los sucesos, de las fuerzas naturales, de lo que le imponen o simplemente le proponen y sugieren los pueblos intensos y expansivos (Masferrer, 1971, p. 454).

Masferrer (1971) es radical al referirse a este tipo de hombres y pueblos afirmando que

Un pueblo así no inventa ni crea nada: cambia sus modas, sus gustos, sus hábitos, cada vez que le llega de fuera la sugestión o la imposición de cambiarlos; adquiere ideas y creencias nuevas, apenas recibe la leve influencia de la voluntad exterior; su ademán, su tono social, su idioma, hasta su comida y su bebida, serán otros, apenas el interés o simplemente el espíritu dominador de fuera le presente nuevos modelos, nuevas formas, nuevos moldes en que vaciar su arcilla amasable e impersonal. (pp. 454-455)

Masferrer es muy actual en su crítica a la vida de los pueblos tropicales y a la experiencia vivida y padecida en El Salvador de la primera mitad del siglo XX. Es más, podría pensarse que nuestro autor está influenciado por el pensamiento colonialista que en su mejor expresión de "colonialidad del poder" constituye el dinamismo propio del desarrollo capitalista europeo desde hace alrededor de quinientos años, de donde el saber y el poder están centralizados desde el continente europeo y que Masferrer siendo hijo de su tiempo, actúa motivado por esa forma de dominación cultural (Masferrer, 1971). Esta situación es una posibilidad real y en el caso salvadoreño, ha llevado al país y a su población a una práctica lamentable, de acuerdo a la opinión de Masferrer, ya que para él, un pueblo como éste

No tiene alma propia, no tiene carácter, no tiene individualidad, y si no los adquiere o desenvuelve, su destino en la historia está marcado ya: ser materia prima que amasarán y manipularán los pueblos originales; y mientras llega la hora de caer entre sus dedos vigorosos e inflexibles, ser una caricatura, una pantomima perenne en la cual se juega la cultura, imaginándose que aquel copiar y recibir constantemente las formas que de fuera le llegan, es civilización y progreso, cuando, en verdad, es solo pantomima. (Masferrer, 1971, p. 455).

Masferrer es consciente de esta realidad padecida en El Salvador; éste es el diagnóstico real, no elucubraciones de un espíritu perdido en la penumbra y en reflexiones vacías. Ante tal situación ve una solución clara en la educación del pueblo. Ésta debe ser conducida por los dirigentes del pueblo. Y ambos, pueblo y dirigencia deben iniciar el proceso cabal de la construcción de la verdadera patria salvadoreña (Masferrer, 1971). 
No obstante, Masferrer reconoce que por el momento el país vive bajo un "imperio nefando y torpe de leyes, creencias religiosas, costumbres, tradiciones, prejuicios y rutinas mentales que relegan al niño a segundo término; que le declaran ilegítimo; que se imaginan ascender a la santidad cuando le otorgan la mezquina e inepta caridad de un hospicio" (Masferrer, 1971, p. 483). Imperio obscuro y torpe cuyas clases dominantes en lo económico, social y político, y, aún así, siendo tan poderosos, lo único que otorgan en su generosidad es La farisaica limosna ocasional de juguetes y vestidos, hecha en cantidad y formas infelices, características de una heroica hazaña que llaman previsión social y educación, a la desdichadísima escuela primaria con sus pobres maestros, sus pobres casas, sus pobres instrumentos de trabajo, su pobre enseñanza, su pobre presupuesto y su pobrísima comprensión de los derechos y de las necesidades del niño" (Masferrer, 1971). Entonces, qué podemos esperar de esta sociedad en el futuro próximo, puesto que lo único que tenemos es todo eso "y lo vamos llevando como un trofeo; como una flor de civilización cristiana y de filosofía y de ciencia. (Masferrer, 1971, p.458).

Entonces, pues, "si la educación, en vez de ser la torpe y tiránica deformación que es hoy, fuera el cultivo prudente, atinado y desinteresado de cada uno, según la ley de sus naturales y más salientes aptitudes," (Masferrer, 1971, p. 459), entonces el futuro del país se encaminaría a la construcción del verdadero progreso y desarrollo, como es el discurso de las clases políticas dirigentes. Eso es lo que se logrará con una educación vitalista, de acuerdo a la perspectiva del Minimumvitalismo Masferreriano.

En esta perspectiva, y con el interés de que la sociedad se organice más humanamenteyse eduque en el espíritu vitalista, Masferrer participa con lecciones magistrales en la Universidad Popular, plataforma con la que desarrollan varias campañas de alfabetización. Pero Masferrer sabe que la cultura no puede llegar en modo efectivo a las masas si no cambia la base económica de la sociedad. No se trata simplemente de un problema de cultura sino de un problema social, de un problema económico, porque el alfabetismo está vinculado profundamente al régimen social, a la infraestructura de la sociedad. Aquí es donde Masferrer articula los preceptos que deben respetar y hacer práctica todos los vitalistas que se incorporen al Partido Vitalista y a los Círculos vitalistas (Masferrer, 1971). Por ello, "nuestro derecho y lo que conviene al desarrollo moral de la humanidad, no es castigar al que ande errado, sino esclarecerle. Puesto que su yerro viene de la ignorancia, lo que procede es iluminarle para que vea su yerro y enderece su camino" (Masferrer, 1971, p. 47). 
El 5 de enero de 1932, quince días antes de llevarse a cabo una de las mayores masacres sucedidas en el siglo XX en América latina, Masferrer dictó una conferencia sobre el Vitalismo en Hispanoamerica y cómo el Minimum Vital se debía incorporar a la vida social, política, educativa, económica en el continente. Anunciaba asimismo la preparación de un estudio que denominaría Economía del Minimum Vital en el que diría las reformas económicas, políticas y educacionales para que el Minimum Vital se realice concretamente.

\section{Conclusión}

Masferrer realizó sus ideas educativas, económicas, sociales y ético-políticas, desde la justicia social y el bien común. Buscó instrumentos institucionales que permitieran una real distribución del ingreso obtenido con el producto del trabajo del obrero salvadoreño. Y afirmó que esto es preciso ejecutarlo por medio del mejoramiento de dicha devolución a través de la cualificación de la cultura y la asistencia social: educación, salud y vivienda. Habló de la libertad humana como la esencia misma del ser humano. Y habló de los derechos naturales del ser humano desde lo alto del valor total de la vida: Vitalismo entendido como vida para todos.

Para Masferrer la justicia social es la forma simple y sencilla de devolver al pueblo parte de aquello que el mismo pueblo ha producido con su trabajo, a fin de que llene sus necesidades primordiales que es, como ya quedó explicado, su Minimumvitalismo "definido concretamente, Mínimun Vital significa la satisfacción constante y segura de nuestras necesidades primordiales" (Masferrer, 1971, p. 190), donde la educación cobra un papel preponderante en la construcción de una sociedad culta.

En este sentido, el pensamiento vitalista masferreriano en cuanto tal, no debe ser considerado localista, correspondiente exclusivamente a la realidad salvadoreña, sino que por el mismo hecho de ser vitalismo en cuanto tal, por sus pretensiones últimas de justicia y radicalidad en el respeto y la promoción de la vida en todas sus expresiones es también un quehacer intelectual centroamericano y mundial.

Para Masferrer, ascender a una sociedad más culta en El Salvador y en Centro América es alcanzable únicamente por la labor ingente de un Hombre Nuevo cuya labor individual no se termina en una reflexión intimista y solipsista, sino en una actividad política en el puro sentido del término, una actividad que tiene que ver con educar a la polis. Esto es lo que jalona la nueva realidad constituida por la justicia concretada en la realidad que permite en definitiva la vida buena para todos. 


\section{Referencias}

Casaús Arzú, M.E. (2012). El Libro de la vida de Alberto Masferrer y otros escritos vitalistas. Guatemala: F\&G Editores.

Dalton, R. (1972). Miguel Mármol, los sucesos de 1932 en El Salvador. Costa Rica: EDUCA.

Hirschberger, J. (1992). Historia de la Filosofía, Tomo II. Barcelona: Editorial Herder. López, M. (1962). Interpretación social del arte. El Salvador: Dirección de Publicaciones e Impresos.

Masferrer, A. (1971). Obras Escogidas, I-II. San Salvador: Editorial Universitaria.

Masferrer, A. (1929, octubre 4). Pega, pero escucha. Patria, pp. 1-2.

Ortega y Gasset, J. (2004). Meditaciones del quijote. En Garagorri, P. (ed). Obras Completas, Tomo I (p. 322). Madrid: Alianza Editorial.

Urdanoz, T. (1998). Historia de la Filosofía, Siglo XX, De Bergson al final de existencialismo, Tomo VI. Madrid: Biblioteca de Autores Cristianos. 